\title{
Improving the enzymatic hydrolysis of thermo-mechanical fiber from Eucalyptus urophylla by a combination of hydrothermal pretreatment and alkali fractionation
}

\author{
Shaoni Sun ${ }^{1}$, Xuefei $\mathrm{CaO}^{2}$, Shaolong Sun ${ }^{1}$, Feng Xu ${ }^{1}$, Xianliang Song ${ }^{1}$, Run-Cang Sun ${ }^{1,2^{*}}$ and Gwynn Lloyd Jones ${ }^{3}$
}

\begin{abstract}
Background: The recalcitrance of lignocellulosic biomass is a major limitation for its conversion into biofuels by enzymatic hydrolysis. The use of a pretreatment technology is an essential step to diminish biomass recalcitrance for bioethanol production. In this study, a two-step pretreatment using hydrothermal pretreatment at various temperatures and alkali fractionation was performed on eucalyptus fiber. The detailed chemical composition, physicochemical characteristics, and morphology of the pretreated fibers in each of the fractions were evaluated to advance the performance of eucalyptus fiber in enzymatic digestibility.

Results: The hydrothermal pretreatment $\left(100\right.$ to $\left.220^{\circ} \mathrm{C}\right)$ significantly degraded hemicelluloses, resulting in an increased crystallinity of the pretreated fibers. However, as the pretreatment temperature reached $240^{\circ} \mathrm{C}$, partial cellulose was degraded, resulting in a reduced crystallinity of cellulose. As compared to the hydrothermal pretreatment alone, a combination of hydrothermal and alkali treatments significantly removed hemicelluloses and lignin, resulting in an improved enzymatic hydrolysis of the cellulose-rich fractions. As compared with the raw fiber, the enzymatic hydrolysis rate increased 1.1 to 8.5 times as the hydrothermal pretreatment temperature increased from 100 to $240^{\circ} \mathrm{C}$. Interestingly, after a combination of hydrothermal pretreatment and alkali fractionation, the enzymatic hydrolysis rate increased 3.7 to 9.2 times. Taking into consideration the consumption of energy and the production of xylo-oligosaccharides and lignin, an optimum pretreatment condition was found to be hydrothermal pretreatment at $180^{\circ} \mathrm{C}$ for 30 min and alkali fractionation with $2 \% \mathrm{NaOH}$ at $90^{\circ} \mathrm{C}$ for $2.5 \mathrm{~h}$, in which $66.3 \%$ cellulose was converted into glucose by enzymatic hydrolysis.
\end{abstract}

Conclusions: The combination of hydrothermal pretreatment and alkali fractionation was a promising method to remove hemicelluloses and lignin as well as overcome the biomass recalcitrance for enzymatic hydrolysis from eucalyptus fiber. In addition, the various techniques applied in this work constituted an efficient approach to understand the underlying chemical and morphological changes of the cellulose-rich fractions.

Keywords: Eucalyptus fiber, Hydrothermal pretreatment, Alkali fractionation, Enzymatic hydrolysis

\footnotetext{
* Correspondence: rcsun3@bjfu.edu.cn

'Beijing Key Laboratory of Lignocellulosic Chemistry, Beijing Forestry

University, Beijing 100083, China

${ }^{2}$ State Key Laboratory of Pulp and Paper Engineering, South China University

of Technology, Guangzhou 510640, China

Full list of author information is available at the end of the article
}

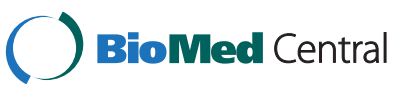

(c) 2014 Sun et al.; licensee Springer ; licensee BioMed Central Ltd. This is an Open Access article distributed under the terms of the Creative Commons Attribution License (http://creativecommons.org/licenses/by/4.0), which permits unrestricted use, distribution, and reproduction in any medium, provided the original work is properly credited. The Creative Commons Public Domain Dedication waiver (http://creativecommons.org/publicdomain/zero/1.0/) applies to the data made available in this article, unless otherwise stated. 


\section{Background}

Lignocellulosic biomass, the most abundantly renewable resource in the world, is a promising alternative to fossil resources for the production of energy, materials, and chemicals. However, lignocellulosic biomass is recalcitrant to biodegradation due to the rigid and compact structure of the plant cell walls (known as "biomass recalcitrance") [1]. Biomass recalcitrance mainly results from the hard-packed spatial network that serves as a protective bulwark [1]. The presence of substances such as hemicelluloses, lignin, and pectin and their spatial inter-links construct physical barriers to protect cellulose from degradation. It has been found that the factors affecting cellulose conversion include lignin, hemicelluloses, the crystallinity and polymerization degree of cellulose, specific surface area, and pore volume, among others [2,3]. Thus, an effective pretreatment technology is crucial to reduce the recalcitrance and make cellulose more available to enzymatic attack.

Different pretreatment methods exist, each with unique action mechanisms, such as removing hemicelluloses and/ or lignin, reducing the cellulose crystallinity, and increasing the biomass surface area. An efficient pretreatment technology should also maximize cellulose recovery from the pretreatment process. Among the various pretreatment methods, hydrothermal treatment combined with alkali treatment is a potential process for effectively fractionating lignocellulosic biomass. According to a biorefinery concept, the process can disrupt the hemicellulose-lignin complex and separate the biomass into main components for further utilization $[4,5]$. Hydrothermal pretreatment has been considered as an environmentally friendly processing technology, since the medium only contains feedstock and water, thus avoiding many problems, such as corrosion and acid recycling [6,7]. In particular, hydrothermal pretreatment can efficiently convert hemicelluloses into soluble compounds that are mainly composed of mono- and oligosaccharides, which could be further hydrolyzed into valueadded chemicals. The solid phase is rich in cellulose and lignin, from which lignin is not removed effectively. As we know, lignin is deemed a significant element affecting enzymatic hydrolysis efficiency due to its high adsorption ability for enzymes [8]. Alkali fractionation has been implemented to effectively solubilize lignin and destroy the rigid structure of lignocellulosic biomass, increasing the availability of cellulose to enzymes. Among various alkalis, sodium hydroxide $(\mathrm{NaOH})$ exhibits the most significant effect on degrading lignin and improving subsequent fermentation yields $[9,10]$. The use of a $\mathrm{NaOH}$ aqueous solution can swell the plant cell walls and disrupt the lignin structure, reduce the degree of polymerization and crystallinity of cellulose, and also increase the surface area of cellulose [11].

In the present study, a two-step consecutive pretreatment was applied to thermo-mechanical fiber from Eucalyptus urophylla to reduce the cellulose recalcitrance and thus improve the enzymatic hydrolysis efficiency. This process included hydrothermal pretreatment under different conditions (temperature and time) predominantly to remove hemicelluloses, followed by alkali $(\mathrm{NaOH})$ fractionation to remove lignin. The hydrothermal pretreated fibers and cellulose-rich fractions were then subjected to enzymatic hydrolysis to evaluate the effect of the hydrothermal and alkali treatments. The chemical composition, physicochemical characteristics, morphology, and enzymatic digestibility of the pretreated samples were detected in order to understand the chemical and structural changes of the cellulose fiber. Figure 1 shows the schematic representation of the hydrothermal pretreatment and alkali fractionation of eucalyptus fiber used in this work.

\section{Results and discussion}

Mass loss and chemical composition of the pretreated fibers and inhibitors in hydrothermal liquor

Hydrothermal pretreatment was utilized to remove hemicelluloses and break up the compact structure of

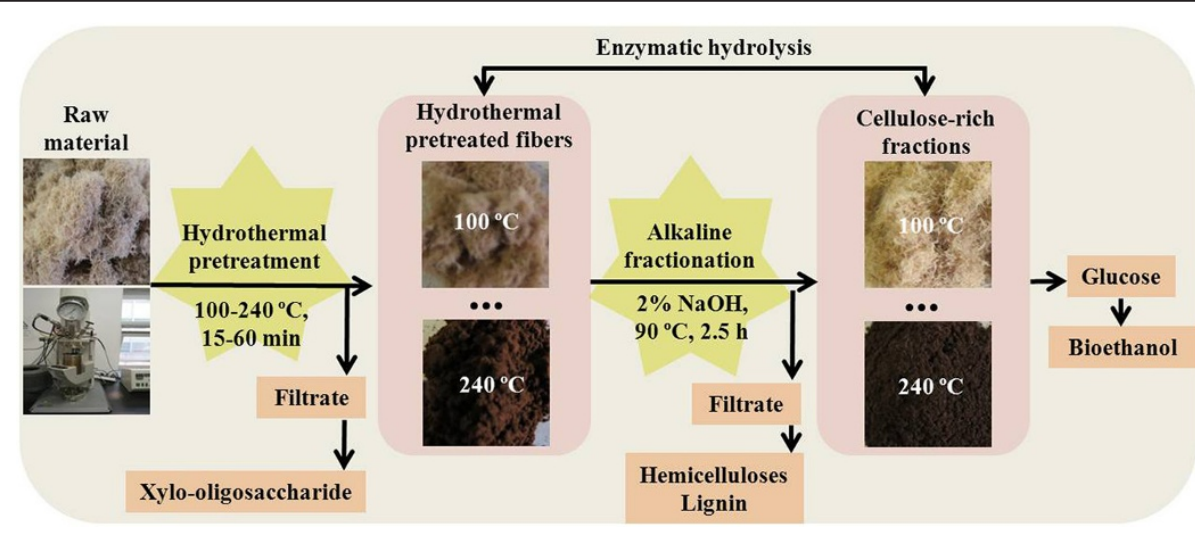

Figure 1 Schematic representation of the processing of eucalyptus fiber by hydrothermal pretreatment and alkali fractionation. 
the biomass. As shown in Figure 2, the dry mass loss increased gradually with temperature. After pretreatment at $100^{\circ} \mathrm{C}$ for $60 \mathrm{~min}\left(\mathrm{R}_{100-60}\right)$, only $1.1 \%$ biomass was consumed by hot water, but more than $50 \%$ biomass was lost after pretreatment at $240^{\circ} \mathrm{C}$ for $30 \mathrm{~min}$ $\left(\mathrm{R}_{240-30}\right)$. As expected, hemicelluloses remaining in the pretreated samples decreased with an increase of temperature and almost disappeared when the pretreatment temperature was higher than $200^{\circ} \mathrm{C}$ (Additional file 1: Table S1). Ibbett and Merali et al. [12,13] reported that hemicelluloses were dissolved as small molecular weight oligomers during hydrothermal pretreatment. At a high temperature, water autoionization generates hydronium ions $\left(\mathrm{H}_{3} \mathrm{O}^{+}\right)$, leading to hydrolysis and deacetylation of hemicelluloses, in which $\mathrm{H}_{3} \mathrm{O}^{+}$is further generated from the released acetic acid to improve hemicellulose degradation. Compared to the hemicelluloses, when the temperature was below $200^{\circ} \mathrm{C}$, the cellulose and total lignin contents in the hydrothermal pretreated fibers were reduced slightly. As the temperature further increased, the percentage of cellulose removal rose markedly and reached a maximum value $(58.7 \%)$ at $240^{\circ} \mathrm{C}$. After hydrothermal pretreatment $\left(100\right.$ to $\left.180^{\circ} \mathrm{C}\right)$, the cellulose content in the residues was increased continuously from $43.91 \%$ to $59.69 \%$ (Additional file 1: Table S1). The organic acids formed during the hydrothermal pretreatment might catalyze the hydrolysis of glycosidic bonds in hemicelluloses to mono- and oligosaccharides and thereby relatively increase the cellulose content. Furthermore, the removal of hemicelluloses from the surface of cellulosic microfibers might also lead to an increment of cellulose pore volume. However, when the pretreatment temperature reached $200^{\circ} \mathrm{C}$, the content of cellulose decreased, which was probably due to the degradation of small amounts of cellulose under the harsh conditions. The lignin content in the pretreated residues increased from 25.84 to $54.35 \%$ with increasing temperature (Additional file 1: Table S1), which was mainly due to the removal of hemicelluloses. It should be noted that a similar degree of removal of cellulose and acid insoluble lignin (AIL) was observed under mild conditions (temperature $<200^{\circ} \mathrm{C}$ ). However, when the pretreatment temperature increased above $200^{\circ} \mathrm{C}$, cellulose was more susceptible to the pretreatment temperature. The hydrothermal pretreatment at 100 to $180^{\circ} \mathrm{C}$ resulted in 0.9 to $13.2 \%$ lignin removal. The noticeable degradation of lignin was presumably a crucial prerequisite for the efficient removal of hemicelluloses, since lignin was covalently associated with hemicelluloses. In contrast, lignin removal decreased sharply to $0.9 \%$ at $240^{\circ} \mathrm{C}$, which was due to the condensation of lignin and precipitation of the dissolved lignin fragments on the surface of cellulose [14]. Furthermore, the percentage of removal of AIL and acid soluble lignin
(ASL) was significantly different. Generally, ASL is composed of low molecular weight lignin and secondarily formed hydrophilic materials, showing less carbon content than AIL $[15,16]$. Therefore, the difference in the percentage of removal between AIL and ASL might suggest that the lignin structure had been altered during the hydrothermal pretreatment, for example, by linkage cleavage and depolymerization $[17,18]$.

As previously stated, the synergistic effect of hydrothermal pretreatment and alkali fractionation could improve the solubilization of hemicelluloses and lignin [19]. A greater dry mass loss of the hydrothermal pretreated sample than that of the raw material was observed after the alkaline treatment (Figure 2b), which is probably ascribed to the fact that more reactive sites and accessible area were released during the hydrothermal pretreatment. During the alkaline treatment, cleavages of hydrolyzable linkages, such as alpha- and beta-aryl ethers in lignin and glycosidic bonds in carbohydrates, constitute the primary reactions that lead to the dissolution of some lignin and carbohydrates [20]. Specifically, the dry mass losses of hemicelluloses and cellulose were attributed to the "peeling" and hydrolytic reaction, while the enhanced delignification was probably due to the depolymerization and modification of lignin macromolecules [18]. This effect eliminated the nonproductive adsorption sites of cellulose and then increased the accessibility. The combination of hydrothermal pretreatment and alkali fractionation resulted in the AIL and ASL decreasing from 25.84 to $54.35 \%$ and 0.42 to $1.12 \%$ to 15.06 to $47.79 \%$ and 0.15 to $0.96 \%$, respectively (Additional file 1: Table S1). Based on the above results, a combination of hydrothermal and alkali treatments could remove more hemicelluloses and lignin than the hydrothermal pretreatment alone, thus resulting in a high glucan content in the cellulose-rich fractions, which would facilitate the subsequent enzymatic saccharification.

During the hydrothermal pretreatment process, some inhibitors were generated, especially at higher pretreatment temperatures. The concentrations of the main inhibitors, including acetic acid, furfural, and 5-hydroxymethylfurfural (HMF), are listed in Additional file 2: Table S2. Acetic acid was formed as a consequence of hydrolysis of the acetyl groups from the hemicellulosic polymers, while furfural and HMF were generated from the dehydration of pentose and hexose, respectively. The concentration of furfural was always higher than that of HMF, which was attributed to the easier dehydration of pentose. As expected, the concentrations of the three inhibitors increased with increasing temperature and time, and their maximal concentrations were observed at $240^{\circ} \mathrm{C}$ for $30 \mathrm{~min}$, corresponding to the harshest experimental conditions in this work. It should be noted that these inhibitors, under the concentration levels given, did not induce any significant inhibition of the activity of the various fermentative microorganisms, since the 

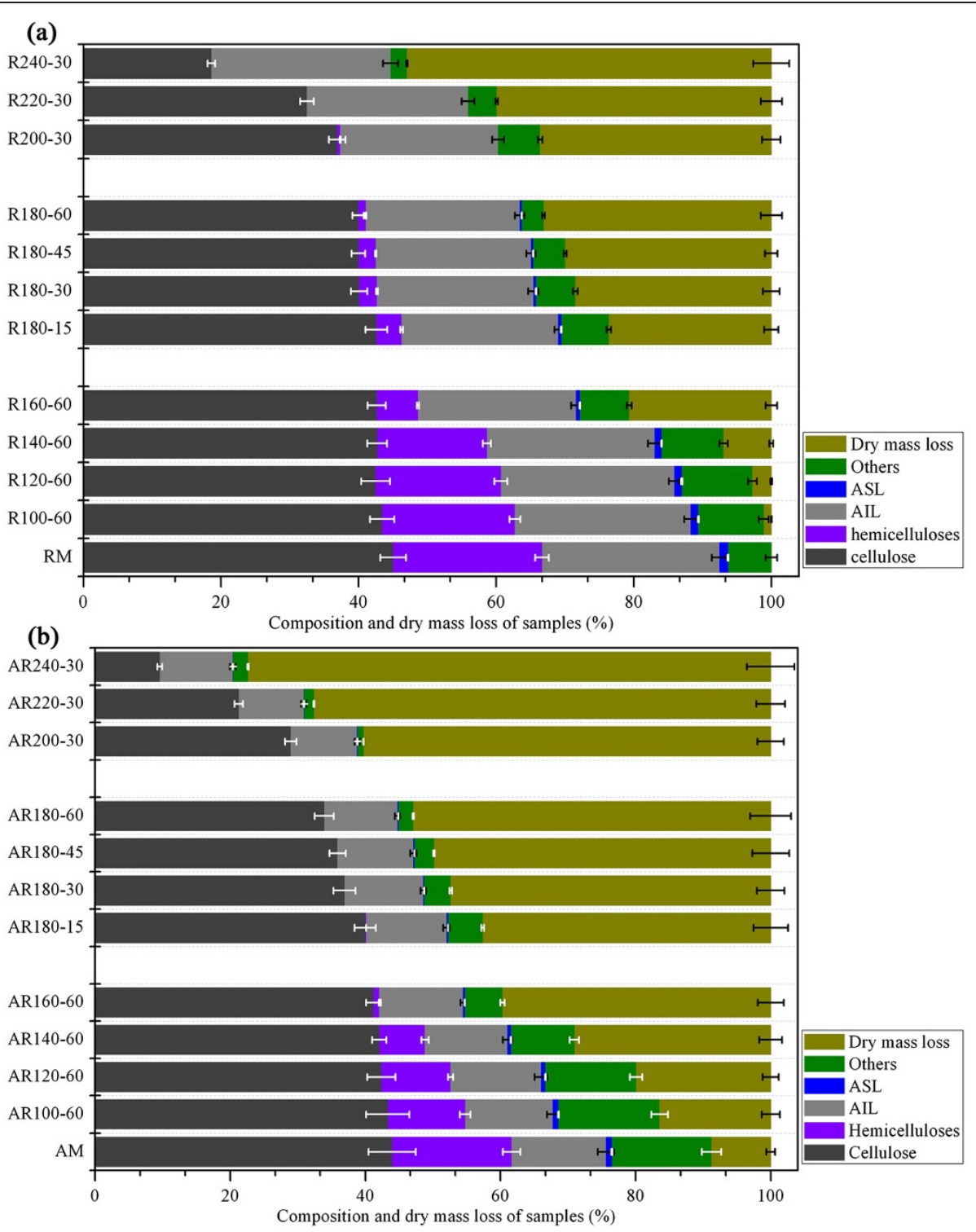

Figure 2 Composition (\% dry mass) and dry mass loss of hydrothermal pretreated fibers (a) and synergistic pretreated samples (b). RM: raw material; R: residues obtained after the direct hydrothermal pretreatment of the raw material; AM: residue obtained after the direct alkali treatment of the raw material without hydrothermal pretreatment; AR: residues obtained after the combination of hydrothermal pretreatment and alkali treatment of the raw material. For chemical compositions of the raw fiber, hydrothermal pretreated fibers, and the cellulose-rich fractions obtained after synergistic treatment, see Additional file 1: Table S1.

solid residue was made almost free of inhibitors by thoroughly washing it with hot water and by following the hydrothermal pretreatment with the alkali treatment.

\section{Physicochemical characteristics of the hydrothermal} pretreated fibers and the cellulose-rich fractions obtained after the synergistic treatment

Fourier transform infrared spectroscopy (FTIR) analysis was utilized to investigate the effects of hydrothermal pretreatment and alkaline fractionation on the chemical structure of biomass (Additional file 3: Figure S1). Characteristic assignments of hemicelluloses at $1738(\mathrm{C}=\mathrm{O}$ conjugates in xylan) and $1244(\mathrm{C}-\mathrm{O}) \mathrm{cm}^{-1}$ were observed in the raw material. The decline of the intensities of the two bands with temperature $\left(100\right.$ to $\left.220^{\circ} \mathrm{C}\right)$ was indicative of the dissolution/removal and/or deacetylation of hemicelluloses [21]. When the hydrothermal pretreatment condition became severe $\left(240^{\circ} \mathrm{C}\right)$, the two peaks almost disappeared, confirming the significant degradation of hemicelluloses. Also, the disappearance of the band at $1738 \mathrm{~cm}^{-1}$ in all of the alkalitreated samples revealed that alkaline treatment cleaved the ester bands of hemicelluloses, such as acetyl and uronic 
ester groups [22]. The intensity of the peak at $1506 \mathrm{~cm}^{-1}$ (skeletal vibrations of the lignin aromatic rings) increased with the increment of the pretreating temperature and time, which was attributed to an increase of the lignin concentration in the hydrothermal pretreated fibers. Additionally, a decreasing intensity of this peak in the cellulose-rich fractions was probably due to the significant removal of lignin during the alkaline fractionation process. A slight decline in the intensity of the peak at $1373 \mathrm{~cm}^{-1}(\mathrm{C}-\mathrm{H}$ deformation in cellulose and hemicelluloses) was observed as a function of temperature and of time. Moreover, a decreasing intensity at $1244 / 1232 \mathrm{~cm}^{-1}$ originating from $\mathrm{C}-\mathrm{O}$ bending vibration in hemicelluloses indicated the decreasing hemicellulose content, which was in accordance with the results obtained by chemical composition analysis. However, a band at around $1036 \mathrm{~cm}^{-1}$, attributed to guaiacyl units of lignin, was observed and gradually increased with temperature. Also, the intensity of the typical cellulose peak at $1161 \mathrm{~cm}^{-1}$ rose as the temperature increased, which resulted from the removal of hemicelluloses and lignin [23].

The crystallinity index (CrI) values of the untreated and pretreated fibers were calculated (Table 1), and their X-ray diffraction (XRD) patterns are shown in Additional file 4: Figure S2. The CrI of the untreated fiber, containing a large amount of amorphous components (mainly hemicelluloses and lignin), was $57.02 \%$. The CrI successively increased with temperature $\left(100\right.$ to $\left.220^{\circ} \mathrm{C}\right)$, which could be attributed to the removal of hemicelluloses, as confirmed by the chemical composition and FTIR analysis. However, the CrI value of $R_{240-30}$ decreased, which was mainly attributed to the partial degradation of crystal cellulose and extensive condensation and re-precipitation of lignin on the surface of cellulose compared to the other samples. Moreover, as compared to the untreated sample, the alkali-treated sample without hydrothermal pretreatment exhibited a high CrI (63.06\%). When the hydrothermal pretreated residues $\left(\mathrm{AR}_{100-60}\right.$ to $\left.A R_{240-30}\right)$ were subjected to alkali treatment, their crystallinities increased slightly (63.06 to $72.94 \%$ ) compared to those of $R_{100-60}$ to $R_{240-30}$ (57.52 to $71.75 \%$ ). The increase in CrI was mainly attributed to the increase in cellulose concentration of the pretreated sample because of the removal of hemicelluloses and lignin (ranging from 25.79 to $54.35 \%$ to 16.98 to 47.79\%) under the alkali conditions. Chen et al. [24] reported that $\mathrm{NaOH}$ treatment increased the CrI because certain amounts of amorphous materials (xylan and lignin) were dissolved by the $\mathrm{NaOH}$ treatment.

Further information on structural changes in the samples that occurred as a consequence of hydrothermal pretreatment and alkali fractionation was obtained by high resolution solid state cross-polarization/magic angle spinning ${ }^{13} \mathrm{C}$ nuclear magnetic resonance $\left(\mathrm{CP} / \mathrm{MAS}{ }^{13} \mathrm{C}\right.$ NMR) (see Figure 3). The signals at 88.8 and 64.9 ppm originate from $\mathrm{C} 4$ and $\mathrm{C} 6$ carbons from the crystalline interior of cellulose microfibrils, whereas the peaks at 83.4 and $62.8 \mathrm{ppm}$ are assigned to $\mathrm{C} 4$ and $\mathrm{C} 6$ carbons in less-ordered cellulose on the surface of microfibrils and hemicellulose [25]. The intensities of C4/C6 signals of the less-ordered cellulose declined slightly with temperature, suggesting that considerable removal of amorphous cellulose and hemicelluloses occurred during the pretreatment process. In this work, the ratio of the area of the 86 to $92 \mathrm{ppm}$ to 80 to $92 \mathrm{ppm}$ region was also calculated as crystallinity [26]. The CrI values of samples from the two measurement techniques were different. Park et al. [27] reported that the crystallinity from the XRD peak height method was higher than that obtained from the CP/MAS ${ }^{13} \mathrm{C}$ NMR method, since NMR technology takes into account the cellulose chains present on the surface of cellulose crystals. However, a similar trend could be observed for these samples; that is, CrI successively increased with

Table 1 The crystallinity indexes of the raw fiber, hydrothermal pretreated fibers, and the cellulose-rich fractions obtained after the synergistic treatment

\begin{tabular}{llllll}
\hline & XRD-Crl (\%) & NMR-Crl (\%) & & XRD-Crl (\%) & NMR-Crl (\%) \\
\hline$R M$ & 57.02 & 43.71 & $A M$ & 59.79 & 46.45 \\
$R_{100-60}$ & 57.52 & 45.26 & $\mathrm{AR}_{100-60}$ & 63.06 & 46.47 \\
$R_{120-60}$ & 58.31 & 46.39 & $\mathrm{AR}_{120-60}$ & 65.24 & 46.66 \\
$\mathrm{R}_{140-60}$ & 60.83 & 46.79 & $\mathrm{AR}_{140-60}$ & 66.30 & 47.22 \\
$\mathrm{R}_{160-60}$ & 62.98 & 49.69 & $\mathrm{AR}_{160-60}$ & 66.75 & 50.74 \\
$\mathrm{R}_{180-15}$ & 67.04 & 50.59 & $\mathrm{AR}_{180-15}$ & 67.90 & 52.73 \\
$\mathrm{R}_{180-30}$ & 68.05 & 51.48 & $\mathrm{AR}_{180-30}$ & 68.23 & 52.83 \\
$\mathrm{R}_{180-45}$ & 68.15 & 51.71 & $\mathrm{AR}_{180-45}$ & 69.23 & 52.97 \\
$\mathrm{R}_{180-60}$ & 69.78 & 53.45 & $\mathrm{AR}_{180-60}$ & 69.26 & 53.53 \\
$\mathrm{R}_{200-30}$ & 70.88 & 54.41 & $\mathrm{AR}_{200-30}$ & 69.91 & 54.37 \\
$\mathrm{R}_{220-30}$ & 71.75 & 55.79 & $\mathrm{AR}_{220-30}$ & 72.94 & 54.82 \\
$\mathrm{R}_{240-30}$ & 68.74 & 53.86 & $\mathrm{AR}_{240-30}$ & 71.53 & 50.75 \\
\hline
\end{tabular}




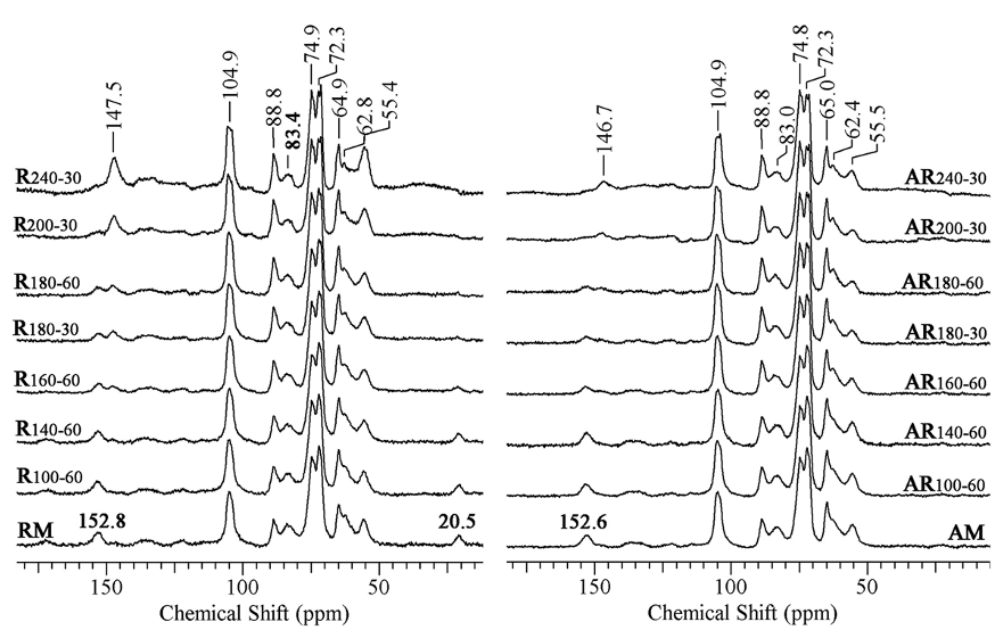

Figure $3 \mathrm{CP} / \mathrm{MAS}{ }^{13} \mathrm{C}$ NMR spectra of the raw fiber, hydrothermal pretreated fibers, and the cellulose-rich fractions.

temperature from 100 to $220^{\circ} \mathrm{C}$ but sharply decreased at $240^{\circ} \mathrm{C}$ (Table 1 ).

Signals from lignin are concentrated in the region of 100 to $200 \mathrm{ppm}$ and are relatively broad due to the chemical complex and disordered structure. Signals for lignin were observed at 152.8 (syringyl lignin), 147.5 (guaiacyl lignin), and 55.4 (methoxy groups) ppm, respectively. The decreasing intensity at $152.8 \mathrm{ppm}$ and increasing intensity at $147.5 \mathrm{ppm}$ implied that the relative content of syringyl units of lignin in the hydrothermal pretreated samples decreased, while that of the guaiacyl units increased. Moreover, after the alkali treatment, the intensity of the guaiacylunits signal was reduced significantly, suggesting that alkali fractionation had an active role in the removal of guaiacyl lignin. Coinciding with the changes in chemical composition, the lignin signals of $\mathrm{R}_{240-30}$ were more pronounced and differentiated compared to the other samples, which was closely related to the recalcitrance of lignin to the autohydrolysis at a high temperature. Also, the spectrum of RM showed two weak peaks at 20.5 and $172.1 \mathrm{ppm}$ for methyl and carboxylic carbons of acetyl groups attached to hemicelluloses [28,29], and the intensities of the two resonances decreased with the degradation of hemicelluloses at higher temperature, as confirmed by FTIR analysis. Moreover, the two signals disappeared in the alkali-treated samples, implying the removal of acetyl groups in hemicelluloses. Peng et al. [30] reported that the cleavage of $O$-acetyl groups occurred and all acetyl groups were split off under alkali conditions. The cleavage of acetyl groups might reduce the steric obstacles of hemicelluloses for enzymatic hydrolysis, possibly increasing the sugar conversion in enzymatic hydrolysis [31,32].

\section{Morphological analysis}

Scanning electron microscopy (SEM) images of the biomass before and after hydrothermal pretreatment and alkali treatment are shown in Figure 4. As can be seen, the RM displayed a compact and regular surface structure and fibers arranged in bundles, which impeded the accessibility of cellulase to cellulose. The hydrothermal pretreatment resulted in evident damage to the plant cell structure, which would benefit enzymatic digestibility of the pretreated fiber. The morphology of $R_{120-60}$ was similar to that of RM because of the limited impact of pretreatment under the mild conditions. At higher temperatures $\left(160^{\circ} \mathrm{C}\right.$ for $60 \mathrm{~min}$ and $180^{\circ} \mathrm{C}$ for $30 \mathrm{~min}$ ), the surfaces of the samples were partially destroyed, as shown by the presences of cracks and small debris. A possible reason was the partial removal of hemicelluloses and lignin during the hydrothermal pretreatment. Under harsher conditions $\left(240^{\circ} \mathrm{C}\right)$, the SEM image shows wellbroken fibers and an increased surface area as compared with the other hydrothermal pretreated samples.

Clearly, there was no obvious change in the surface structure between RM and AM. After a low temperature pretreatment $\left(100^{\circ} \mathrm{C}\right)$, the alkali-treated sample $\mathrm{AR}_{100-60}$ exhibited slightly morphological changes on the surface of the fibers. When the pretreatment temperature increased to 160 and $180^{\circ} \mathrm{C}$, some minor debris on the fiber surfaces was removed, and the surface structure of the alkali-treated samples tended to be smooth, resulting in the exposure of more fiber bundles; thus, the accessibility of fiber bundles to cellulase could be improved. After pretreatment at $240^{\circ} \mathrm{C}$, the cellulose structure of $\mathrm{AR}_{240-30}$ was damaged and more small pieces were generated. Overall, the hydrothermal pretreatment shows an obvious effect on hemicellulose removal, while the following alkali fractionation can remove lignin effectively. The removal of both hemicelluloses and lignin resulted in the release of a larger specific surface area, which favored the following enzymatic hydrolysis. 


\section{Enzymatic hydrolysis}

Figure 5 shows the sugar yields from the enzymatic saccharification of the native and pretreated fibers. As expected, the cellulose conversion increased with increasing pretreatment temperature. After $72 \mathrm{~h}$ of hydrolysis, only $10.36 \%$ of glucan was converted into glucose for RM. The conversion rates of the hydrothermal pretreated samples at low temperature $\left(\leq 140^{\circ} \mathrm{C}\right)$ were 11.94 to $13.44 \%$. The alkaline treatment led to a substantial enhancement in enzymatic hydrolysis (38.21 to $46.26 \%$ ). However, the saccharification of the sample AM (treated with alkali alone) was $36.52 \%$, which was higher than those of RM. At 160 to $180^{\circ} \mathrm{C}$, higher glucose yields were obtained and

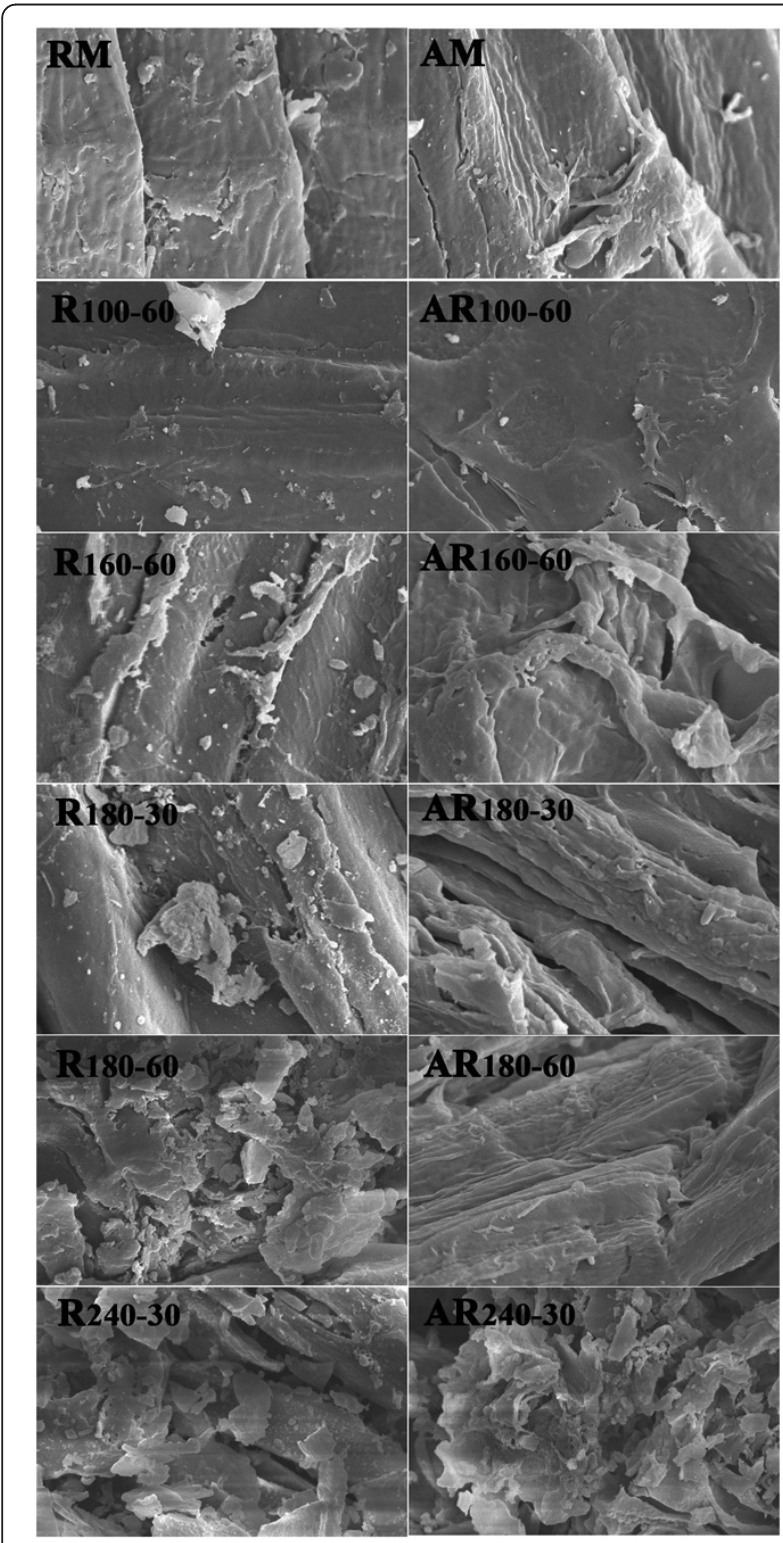

Figure 4 SEM images of the raw fiber, hydrothermal pretreated fibers, and the cellulose-rich fractions at magnification $\times 3000$. the glucose release progressively increased with the pretreatment temperature and time. This enhanced enzymatic hydrolysis was likely attributed to the effective removal of hemicelluloses and the partial removal of lignin, as identified by the data in Figure 2. Lignin affected the enzymatic digestibility effectiveness by inhibiting enzyme function or by acting as an enzymatic trap, which led to an unproductive adsorption of enzymes [33]. Meanwhile, the SEM images showed that hemicellulose and lignin removal led to generations of cracks and small debris on the cellulose fibers, which enhanced the accessibility of substrate to enzyme. After the sequential $\mathrm{NaOH}$ treatment, the enzymatic hydrolysis of the cellulose-rich fractions was significantly improved, which demonstrated that the sequential alkali treatment was beneficial for increasing glucose conversion. Alkali fractionation enhanced the removal of hemicelluloses and lignin from the fibers, reducing the physical barrier and the invalid adsorption of cellulase on lignin. The effective adsorption of cellulase on cellulose, which is the first step in the hydrolysis reaction and a precondition for efficient cellulose conversion $[17,34]$, is closely related to the accessible surface area of cellulose [35]. When the pretreatment temperature increased to $220^{\circ} \mathrm{C}$ or even $240^{\circ} \mathrm{C}$, the enzymatic hydrolysis efficiency of the alkali-treated residue was significantly enhanced compared with the others. The maximal glucose yield of $95.6 \%$ with a low cellulose recovery $(21.3 \%)$ was achieved by the combination of hydrothermal pretreatment at $240^{\circ} \mathrm{C}$ for $30 \mathrm{~min}$ and $2 \% \mathrm{NaOH}$ treatment; this yield was increased by 8.2 times compared with that of the raw material (10.4\%). The high glucose yield was likely due to the serious disintegration of cellulose (as shown in the SEM image), which provided a larger surface area and larger amounts of cellulose chain ends and thus improved enzyme accessibility.

\section{Process mass balance}

A process mass balance of the two-step pretreatment process and the subsequent enzymatic hydrolysis was developed for the four hydrothermal pretreatment conditions (Figure 6). Process yields were normalized to a common basis of $100 \mathrm{~kg}$ of dried eucalyptus fiber as the starting material. After the two-step pretreatment process, the yields of the residual eucalyptus fiber (cellulose-rich fractions) decreased from 60.31 to $39.65 \mathrm{~kg}$ with an increasing pretreatment temperature from $160^{\circ} \mathrm{C}$ to $200^{\circ} \mathrm{C}$. The cellulose-rich fractions were then subjected to enzymatic hydrolysis. It was found that 26.38, 27.19, 28.63, and $25.14 \mathrm{~kg}$ glucose could be obtained when the hydrothermal pretreatment conditions were performed at $160^{\circ} \mathrm{C}$ for $60 \mathrm{~min}, 180^{\circ} \mathrm{C}$ for $30 \mathrm{~min}, 180^{\circ} \mathrm{C}$ for $60 \mathrm{~min}$, and $200^{\circ} \mathrm{C}$ for $30 \mathrm{~min}$, respectively. It should be noted that, after the hydrothermal pretreatment, the liquid and solid were separated by filtration and 1.24 to $7.65 \mathrm{~kg}$ 

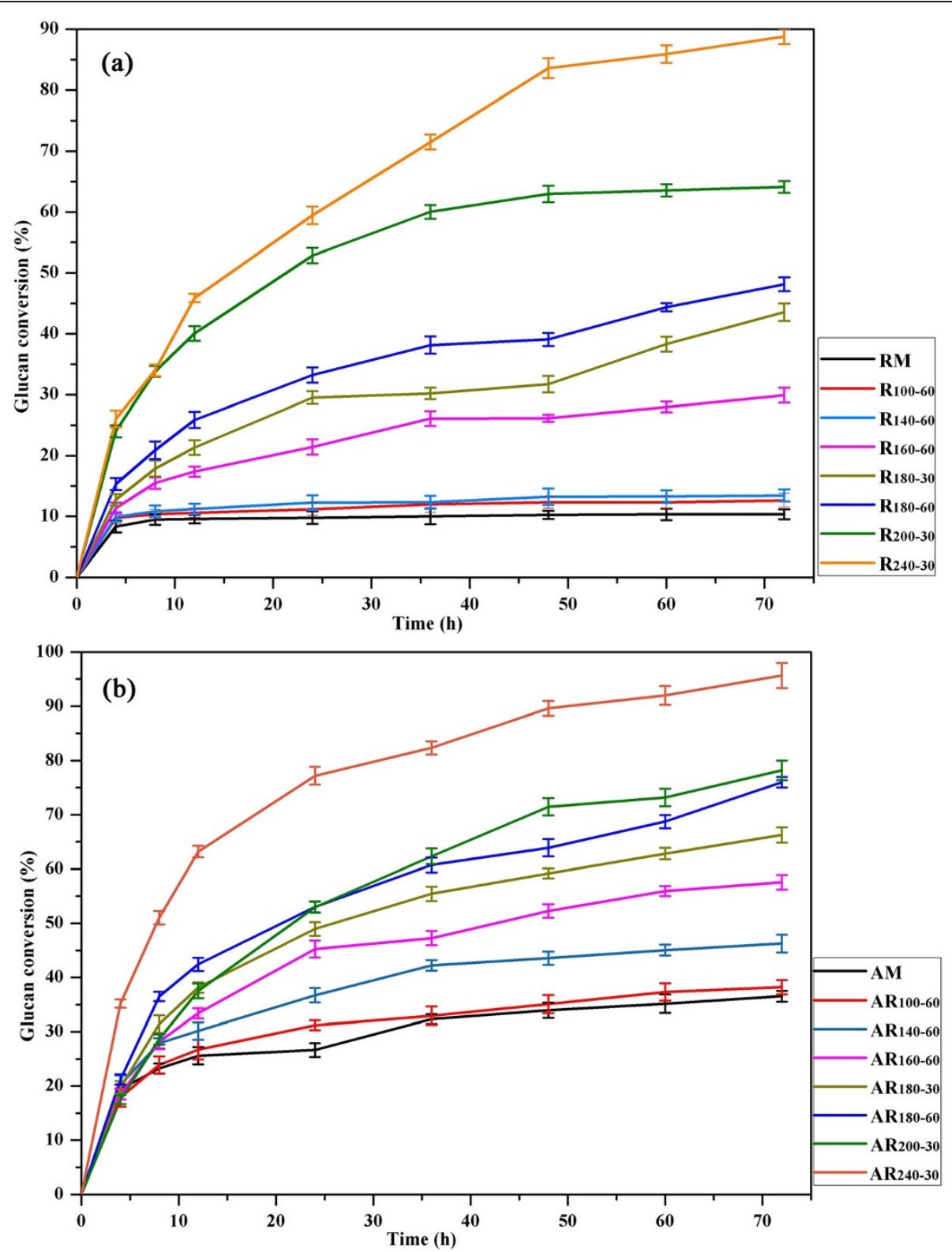

Figure 5 The enzymatic hydrolysis of the fibers after hydrothermal pretreatment (a) and the synergistic treatment (b). The error bars are standard deviations from the average values of duplicate determinations.

xylo-oligosaccharides for $100 \mathrm{~kg}$ of initial fiber was observed in the hydrothermal liquid. Additionally, after subsequent alkali fractionation, 8.14 to $12.22 \mathrm{~kg}$ lignin for $100 \mathrm{~kg}$ of initial fiber was recovered, which could be converted into high-value materials. As we know, the viability of the two-step pretreatment process is strongly correlated to the glucose yield. However, the consumption of energy and the production of xylooligosaccharides and lignin should also be taken into account. Therefore, in this work, a combination of hydrothermal pretreatment at $180^{\circ} \mathrm{C}$ for $30 \mathrm{~min}$ and alkali treatment with $2 \% \mathrm{NaOH}$ was considered as the optimum condition for glucose production and lignin recovery.

\section{Conclusions}

Pretreatment is an important process for improving the digestibility of lignocellulosic biomass. During the hydrothermal pretreatment, it was found that hemicelluloses could be easily removed from the biomass as compared with cellulose and lignin. Moreover, alkali fractionation could significantly reduce the content of lignin in the biomass and remove part of the hemicelluloses. Both hydrothermal pretreatment and alkali fractionation could 

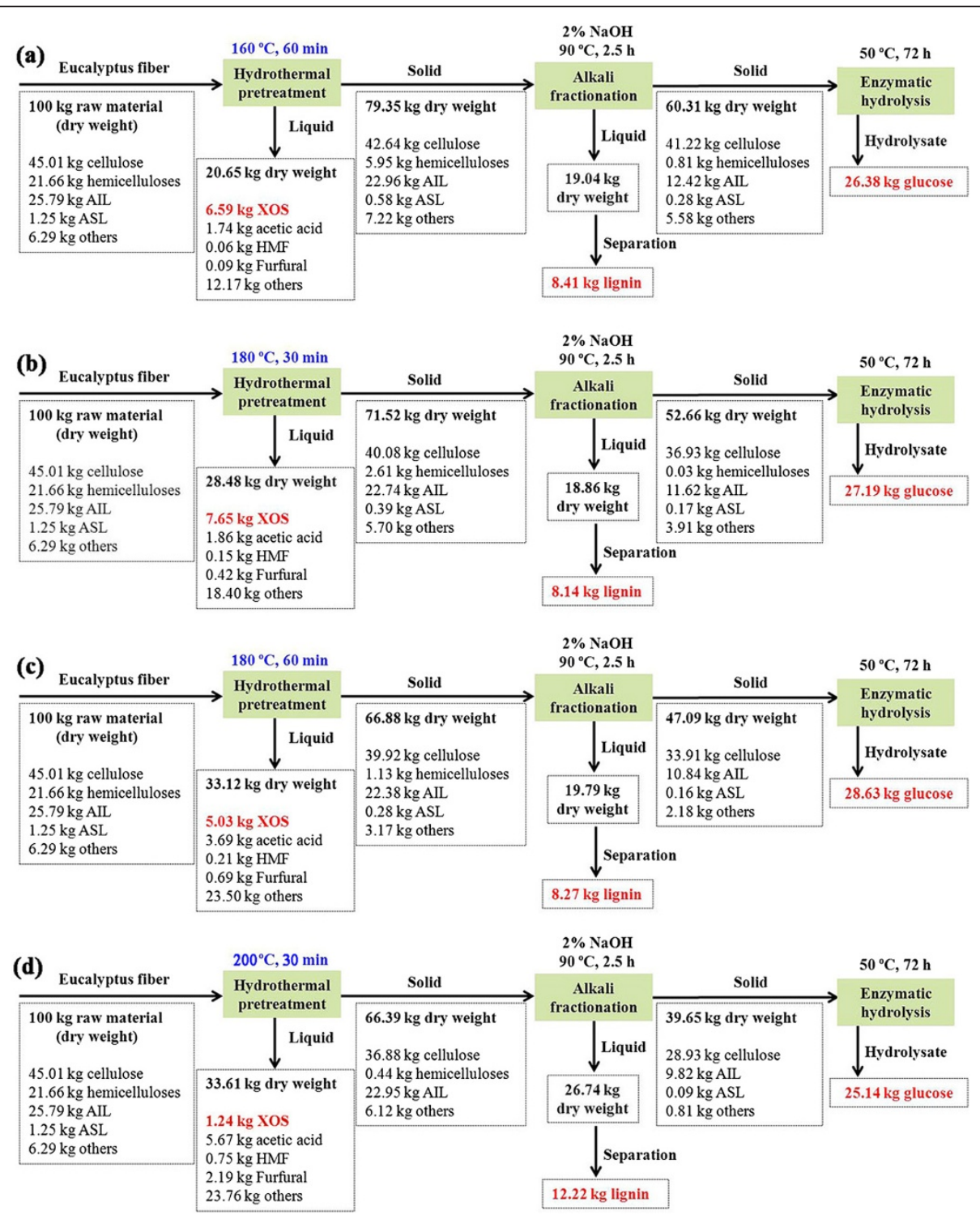

Figure 6 Material balances during the synergistic treatment and enzymatic hydrolysis for the four pretreatment conditions.

(a) Hydrothermal pretreatment at $160^{\circ} \mathrm{C}$ for 60 min combined with the alkali treatment, (b) hydrothermal pretreatment at $180^{\circ} \mathrm{C}$ for 30 min combined with the alkali treatment, (c) hydrothermal pretreatment at $180^{\circ} \mathrm{C}$ for 60 min combined with the alkali treatment, and (d) hydrothermal pretreatment at $200^{\circ} \mathrm{C}$ for 30 min combined with the alkali treatment.

improve the enzymatic digestibility of eucalyptus fiber to some degree. More importantly, the combination of hydrothermal pretreatment and alkali fractionation resulted in a significant synergistic digestibility of eucalyptus fiber over that of the hydrothermal or alkali pretreatment alone. Under the optimal condition of hydrothermal pretreatment at $180^{\circ} \mathrm{C}$ for $30 \mathrm{~min}$ and sequent fractionation with aqueous alkali solution $\left(2 \% \mathrm{NaOH}, 90^{\circ} \mathrm{C}, 2.5 \mathrm{~h}\right), 27.19 \mathrm{~kg}$ fermentable glucose, $7.65 \mathrm{~kg}$ xylo-oligosaccharides, and $8.14 \mathrm{~kg}$ lignin for $100 \mathrm{~kg}$ of initial fiber could be recovered. The enzymatic hydrolysis rate of the treated fibers was enhanced 6.4 times by this combination of hydrothermal pretreatment and alkali fractionation compared to that of the raw material without treatment. Clearly, the combined treatment of hydrothermal pretreatment and alkali fractionation can be considered as a promising approach to achieve the efficient conversion of biomass to fermentable glucose for bioethanol production. Furthermore, the other two major components, xylo-oligosaccharides from hemicelluloses and the recovered lignin, can also be converted into high value-added products.

\section{Methods}

\section{Raw materials}

The thermo-mechanical fiber obtained at $120^{\circ} \mathrm{C}$ for 1 to 2 min from Eucalyptus urophylla, as raw material (RM), 
was kindly supplied by the State Key Laboratory of Pulp and Paper Engineering, South China University of Technology, China. The material was first dewaxed with methylbenzene/ethanol $(2: 1, \mathrm{v} / \mathrm{v})$ in a Soxhlet apparatus for $3 \mathrm{~h}$, and the sample was then dried in an oven for $12 \mathrm{~h}$ at $60^{\circ} \mathrm{C}$ for further use. The eucalyptus fiber consisted of $45.01 \%$ cellulose, $21.66 \%$ hemicelluloses, and $27.04 \%$ total lignin. All chemicals purchased were of analytical or reagent grade and used without further purification.

\section{Hydrothermal pretreatment and alkali fractionation}

The hydrothermal pretreatment experiment was carried out in a laboratory-scale reactor (Parr Instrument Company, Moline, IL, USA) with a maximal volume of $1,000 \mathrm{ml}$. The feedstock $15.0 \mathrm{~g}$ was mixed with $450 \mathrm{ml}$ of distilled water and then heated to 100 (60 $\mathrm{min}), 120$ (60 $\mathrm{min}), 140$ (60 $\mathrm{min}), 160$ (60 $\mathrm{min}), 180$ (15, 30, 45, and $60 \mathrm{~min}), 200(30 \mathrm{~min}), 220(30 \mathrm{~min})$, and $240(30 \mathrm{~min})^{\circ} \mathrm{C}$, respectively, at a heating rate of about $4^{\circ} \mathrm{C} / \mathrm{min}$. Once the desired operation was reached, the reactor was cooled to about $50^{\circ} \mathrm{C}$ by flowing water through an internal stainless steel loop. The liquid stream and solid residue were separated by filtration with a nylon cloth, and the residue was then washed thoroughly with hot water and dried in an oven at $60^{\circ} \mathrm{C}$. The pretreated residues were labeled as $\mathrm{R}_{100-60}, \mathrm{R}_{120-60}, \mathrm{AR}_{140-60}, \mathrm{R}_{160-60}, \mathrm{R}_{180-15}, \mathrm{R}_{180-30}, \mathrm{R}_{180-45}$, $\mathrm{R}_{180-60}, \mathrm{R}_{200-30}, \mathrm{R}_{220-30}$, and $\mathrm{R}_{240-30}$, respectively, according to the pretreatment temperature and time. The liquid product was passed through $0.22-\mu \mathrm{m}$ filters and stored at $-50^{\circ} \mathrm{C}$ for further analysis. In alkali fractionation, the hydrothermal pretreated samples were further treated with $2 \% \mathrm{NaOH}$ at $90^{\circ} \mathrm{C}$ for $2.5 \mathrm{~h}$ with a solid-to-liquid ratio of 1:30 $(\mathrm{g} / \mathrm{ml})$. The insoluble residues were collected by filtration, thoroughly washed and dried, and labeled as cellulose-rich fractions of $\mathrm{AR}_{100-60}, \mathrm{AR}_{120-60}, \mathrm{AR}_{140-60}$, $\mathrm{AR}_{160-60}, \mathrm{AR}_{180-15}, \mathrm{AR}_{180-30}, \mathrm{AR}_{180-45}, \mathrm{AR}_{180-60}, \mathrm{AR}_{200-30}$, $A R_{220-30}$, and $A R_{240-60}$, respectively. For comparison, un-pretreated material was also fractionated using the same alkaline solution and labeled as AM. Additionally, it should be noted that lignins were obtained during the alkali treatment, and the purification procedure of all lignin fractions was performed according to the method of a previous work [36].

\section{Analysis methods}

The composition of the pretreated and un-pretreated samples was determined by the National Renewable Energy Laboratory (NREL) standard analytical procedure [37]. High-performance anion exchange chromatography (HPAEC) was used to quantify the sugars and uronic acids from the liquor obtained by $\mathrm{H}_{2} \mathrm{SO}_{4}$ hydrolysis of all the samples, using a Dionex ICS-3000
HPAEC system equipped with an AS50 autosampler and a CarboPac PA-20 column $(4 \times 250 \mathrm{~mm}$, Dionex) [38].

The liquid obtained by hydrothermal pretreatment without dilution was filtered and stored to determine xylo-oligosaccharides and inhibitory products. A 3-ml liquid sample was subjected to quantitative post-hydrolysis with $4 \% \mathrm{H}_{2} \mathrm{SO}_{4}$ at $121^{\circ} \mathrm{C}$ for $60 \mathrm{~min}$. The increased concentration of monosaccharides caused by post-hydrolysis was regarded as the xylo-oligosaccharides concentration. The inhibitors were quantitatively measured on an HPLC system (Agilent 1200 series, Agilent Technologies, Santa Clara, CA, USA) equipped with a refractive index detector. The HPLC analysis was conducted using an HPX-87H ion exclusion column (with a length of $300 \mathrm{~mm}$ and an inner diameter of $7.8 \mathrm{~mm}$, Bio-Rad, Laboratories, Hercules, CA, USA) operating at $50^{\circ} \mathrm{C}$ with $5 \mathrm{mM}$ sulfuric acid at a flow rate of $0.6 \mathrm{ml} / \mathrm{min}$.

The FTIR spectra of RM and pretreated residues were recorded on a Bruker spectrophotometer in the range of 400 to $4000 \mathrm{~cm}^{-1}$ with a resolution of $4 \mathrm{~cm}^{-1}$. A KBr disc containing $1 \%$ finely ground sample was used for measurement. XRD analyses of all samples were performed on a D8 Advance instrument (Bruker AXS) with Nifiltered $\mathrm{Cu} \mathrm{K} \alpha$ radiation (wavelength $=0.154 \mathrm{~nm}$ ) from $5^{\circ}$ to $60^{\circ}$. The CrI was measured from the XRD data and calculated with the following formula:

$$
\mathrm{CrI}=\frac{\mathrm{I}_{002}-\mathrm{I}_{\mathrm{am}}}{\mathrm{I}_{002}} \times 100
$$

Here $\mathrm{I}_{002}$ is the scattered intensity of cellulose $\mathrm{I}$ at about $2 \theta=22.5^{\circ}$, and $\mathrm{I}_{\mathrm{am}}$ is the peak for the amorphous portion assessed as the minimum intensity between the main and the secondary peaks at $2 \theta=18.5^{\circ}$.

CP/MAS ${ }^{13} \mathrm{C}$ NMR spectra of samples were obtained at $100.6 \mathrm{MHz}$ using a Bruker AV-III $400 \mathrm{M}$ spectrometer (Germany). Dried samples were packed in a 4-mm zirconia $\left(\mathrm{ZrO}_{2}\right)$ rotor, and the measurements were performed using a $\mathrm{CP}$ pulse program with a 1-ms match time and a 2-s delay between transients. The spinning rate was $5 \mathrm{kHz}$. The SEM images were recorded with a Hitachi $3400 \mathrm{~N}$ scanning electron microscope operated at $10 \mathrm{kV}$ and $81 \mathrm{~mA}$. All samples were coated with gold prior to examination.

\section{Enzymatic hydrolysis}

Enzymatic hydrolysis was conducted to comparably investigate the digestibilities of the raw material, hydrothermal pretreated fibers, and the cellulose-rich fractions obtained from the hydrothermal pretreatment and the subsequent alkali treatment. Enzymatic hydrolysis was carried out at $2 \%$ of substrate $(\mathrm{w} / \mathrm{v})$ in $10 \mathrm{ml}$ of $50 \mathrm{mM}$ sodium acetate buffer ( $\mathrm{pH}$ 4.8) using a water bath shaking incubator at $150 \mathrm{rpm}$. The temperature was adjusted 
to $50^{\circ} \mathrm{C}$ for $72 \mathrm{~h}$. The enzymes were cellulase and betaglucosidase for all hydrolysis experiments, and the loadings were $17 \mathrm{FPU} / \mathrm{g}$ and $34 \mathrm{IU} / \mathrm{g}$ based on the dry weight of the substrate. The hydrolyzates were sampled periodically and analyzed by an HPAEC system (Dionex, ICS 3000, USA) on a CarboPac PA-100 analytical column. All enzymatic hydrolysis experiments were performed in duplicate, and the average values and corresponding deviations were given.

\section{Additional files}

Additional file 1: Table S1. Chemical compositions of the raw material, hydrothermal pretreated fibers, and the cellulose-rich fractions.

Additional file 2: Table S2. The concentrations of the inhibitors in the hydrothermal liquids.

Additional file 3: Figure S1. FTIR spectra of the raw material, hydrothermal pretreated fibers, and the cellulose-rich fractions.

Additional file 4: Figure S2. XRD patterns of the raw fiber, hydrothermal pretreated fibers, and the cellulose-rich fractions.

\section{Abbreviations}

AlL: acid insoluble lignin; ASL: acid soluble lignin; CP/MAS ${ }^{13} \mathrm{C}$ NMR: solid state cross-polarization/magic angle spinning ${ }^{13} \mathrm{C}$ nuclear magnetic resonance; Crl: crystallinity index; FTIR: Fourier transform infrared spectroscopy; HPAEC: high-performance anion exchange chromatography; HPLC: high-performance liquid chromatography; NREL: National Renewable Energy Laboratory; RM: raw material; SEM: scanning electron microscopy; XRD: X-ray diffraction.

\section{Competing interests}

The authors declare that they have no competing interests.

\section{Authors' contributions}

SNS performed the major experiments, analyzed the data, and prepared the manuscript. XFC, SLS, FX, XLS, and GLJ helped with the overall pretreatment experiments and the instrumental analysis. RCS designed the project, supervised the experiments, and finalized the manuscript. All authors read and approved the final manuscript.

\section{Acknowledgements}

The authors are extremely grateful for the financial support from the Major State Basic Research Projects of China (973-2010CB732203/4) and the State Forestry Administration (201204803).

\section{Author details}

'Beijing Key Laboratory of Lignocellulosic Chemistry, Beijing Forestry University, Beijing 100083, China. ${ }^{2}$ State Key Laboratory of Pulp and Paper Engineering, South China University of Technology, Guangzhou 510640, China. ${ }^{3}$ School of Natural Science, University of Wales, Gwynedd, Bangor LL57 2UWWales, UK.

Received: 9 April 2014 Accepted: 21 July 2014

Published: 20 August 2014

\section{References}

1. Zhao X, Zhang L, Liu D: Biomass recalcitrance. Part I: the chemical compositions and physical structures affecting the enzymatic hydrolysis of lignocellulose. Biofuel Bioprod Bior 2012, 6:465-482.

2. Masarin F, Gurpilhares DB, Baffa DCF, Barbosa MHP, Carvalho W, Ferraz A Milagres AMF: Chemical composition and enzymatic digestibility of sugarcane clones selected for varied lignin content. Biotechnol Biofuels 2011, 4:55.

3. Sun Y, Cheng J: Hydrolysis of lignocellulosic materials for ethanol production: a review. Bioresour Technol 2002, 83:1-11.
4. Sun $S N$, Cao XF, Zhang XM, Xu F, Sun RC, Jones GL: Characteristics and enzymatic hydrolysis of cellulose-rich fractions from steam exploded and sequentially alkali delignified bamboo (Phyllostachys pubescens). Bioresour Technol 2014, 163:377-380.

5. Rocha GJD, Martin C, Soares IB, Maior AMS, Baudel HM, de Abreu CAM: Dilute mixed-acid pretreatment of sugarcane bagasse for ethanol production. Biomass Bioenerg 2011, 35:663-670.

6. Garrote G, Dominguez H, Parajo JC: Hydrothermal processing of lignocellulosic materials. Eur J Wood Wood Prod 1999, 57:191-202.

7. Gullón P, Romaní A, Vila C, Garrote G, Parajó JC: Potential of hydrothermal treatments in lignocellulose biorefineries. Biofuel Bioprod Bior 2012, 6:219-232.

8. Kumar R, Wyman CE: Access of cellulase to cellulose and lignin for poplar solids produced by leading pretreatment technologies. Biotechnol Progr 2009, 25:807-819.

9. Rodríguez-Vázquez R, Díaz-Cervantes D: Effect of chemical solutions sprayed on sugarcane bagasse pith to produce single cell protein: physical and chemical analyses of pith. Bioresour Technol 1994, 47:159-164.

10. Rodriguez-Vazquez R, Villanueva-Ventura G, Rios-Leal E: Sugarcane bagasse pith dry pretreatment for single cell protein production. Bioresour Technol 1992, 39:17-22.

11. Taherzadeh MJ, Karimi K: Pretreatment of lignocellulosic wastes to improve ethanol and biogas production: a review. Int J Mol Sci 2008, 9:1621-1651.

12. Ibbett R, Gaddipati S, Davies S, Hill S, Tucker G: The mechanisms of hydrothermal deconstruction of lignocellulose: new insights from thermal-analytical and complementary studies. Bioresour Technol 2011, 102:9272-9278.

13. Merali Z, Ho JD, Collins SRA, Gall GL, Elliston A, Käsper A, Waldron KW: Characterization of cell wall components of wheat straw following hydrothermal pretreatment and fractionation. Bioresour Technol 2012, 131:226-234.

14. Oliveira FMV, Pinheiro IO, Souto-Maior AM, Martin C, Goncalves AR, Rocha GJM: Industrial-scale steam explosion pretreatment of sugarcane straw for enzymatic hydrolysis of cellulose for production of second generation ethanol and value-added products. Bioresour Technol 2013, 130:168-173.

15. Matsushita Y, Kakehi A, Miyawaki S, Yasuda S: Formation and chemical structures of acid-soluble lignin II: reaction of aromatic nuclei model compounds with xylan in the presence of a counterpart for condensation, and behavior of lignin model compounds with guaiacyl and syringyl nuclei in 72\% sulfuric acid. J Wood Sci 2004, 50:136-141.

16. Yasuda S, Fukushima K, Kakehi A: Formation and chemical structures of acid-soluble lignin I: sulfuric acid treatment time and acid-soluble lignin content of hardwood. J Wood Sci 2001, 47:69-72.

17. $\mathrm{Xu} C \mathrm{CY}, \mathrm{Ma} F Y$, Zhang XY, Chen SL: Biological pretreatment of corn stover by Irpex lacteus for enzymatic hydrolysis. J Agric Food Chem 2010, 58:10893-10898.

18. Yu H, Du W, Zhang J, Ma F, Zhang X, Zhong W: Fungal treatment of cornstalks enhances the delignification and xylan loss during mild alkaline pretreatment and enzymatic digestibility of glucan. Bioresour Technol 2010 101:6728-6734.

19. Gao YS, XU JL, Zhang Y, Yu Q, Yuan ZH, Liu YY: Effects of different pretreatment methods on chemical composition of sugarcane bagasse and enzymatic hydrolysis. Bioresour Technol 2013, 144:396-400.

20. Mclntosh S, Vancov T: Enhanced enzyme saccharification of Sorghum bicolor straw using dilute alkali pretreatment. Bioresour Technol 2010, 101:6718-6727.

21. Garrote G, Dominguez H, Parajo JC: Study on the deacetylation of hemicelluloses during the hydrothermal processing of Eucalyptus wood. Holz Roh Werkst 2001, 59:53-59.

22. Sun RC, Tomkinson J: Characterization of hemicelluloses obtained by classical and ultrasonically assisted extractions from wheat straw. Carbohyd Polym 2002, 50:263-271.

23. Pandey KK, Nagveni HC: Rapid characterisation of brown and white rot degraded chir pine and rubberwood by FTIR spectroscopy. Holz Roh Werkst 2007, 65:477-481.

24. Chen D, Guo Y, Huang R, Lu Q, Huang J: Pretreatment by ultra-high pressure explosion with homogenizer facilitates cellulase digestion of sugarcane bagasses. Bioresour Technol 2010, 101:5592-5600.

25. Newman RH: Homogeneity in cellulose crystallinity between samples of Pinus radiata wood. Holzforschung 2004, 58:91-96. 
26. Sannigrahi P, Ragauskas AJ, Miller SJ: Effects of two-stage dilute acid pretreatment on the structure and composition of lignin and cellulose in loblolly pine. Bioenergy Res 2008, 1:205-214.

27. Park S, Baker J, Himmel M, Parilla P, Johnson D: Cellulose crystallinity index: measurement techniques and their impact on interpreting cellulase performance. Biotechnol Biofuels 2010, 3:10.

28. Almendros G, Martinez AT, Gonzalez AE, Gonzalez-Vila FJ, Fruend R, Luedemann HD: CPMAS carbon-13 NMR study of lignin preparations from wheat straw transformed by five lignocellulose-degrading fungi. J Agric Food Chem 1992, 40:1297-1302.

29. Gilardi G, Abis L, Cass AEG: Carbon-13 CP/MAS solid-state NMR and FT-IR spectroscopy of wood cell wall biodegradation. Enzyme Microb Technol 1995, 17:268-275.

30. Peng F, Peng P, Xu F, Sun RC: Fractional purification and bioconversion of hemicelluloses. Biotechnol Adv 2012, 30:879-903.

31. Kong F, Engler CR, Soltes EJ: Effect of cell-wall acetate, xylan backbone, and lignin on enzymatic hydrolysis of aspen wood. Appl Biochem Biotechnol 1992, 34/35:23-35.

32. Mitchell DJ, Grohmann K, Himmel ME, Dale BE, Schroeder HA: Effect of the degree of acetylation on the enzymatic digestion of acetylated xylan. J Wood Chem Technol 1990, 10:111-121.

33. Rezende CA, de Lima MA, Maziero P, de Azevedo ER, Garcia W, Polikarpov I: Chemical and morphological characterization of sugarcane bagasse submitted to a delignification process for enhanced enzymatic digestibility. Biotechnol Biofuels 2011, 4:54.

34. Yu H, Guo G, Zhang X, Yan K, Xu C: The effect of biological pretreatment with the selective white-rot fungus Echinodontium taxodii on enzymatic hydrolysis of softwoods and hardwoods. Bioresour Technol 2009, 100:5170-5175.

35. Rollin JA, Zhu Z, Sathitsuksanoh N, Zhang YHP: Increasing cellulose accessibility is more important than removing lignin: a comparison of cellulose solvent-based lignocellulose fractionation and soaking in aqueous ammonia. Biotechnol Bioeng 2011, 108:22-30.

36. Sun SN, Li MF, Yuan TQ, Xu F, Sun RC: Sequential extractions and structural characterization of lignin with ethanol and alkali from bamboo (Neosinocalamus affinis). Ind Crop Prod 2012, 108:51-60.

37. Sluiter A, Hames B, Ruiz R, Scarlata C, Sluiter J, Templeton D, Crocker D: Determination of Structural Carbohydrates and Lignin in Biomass. Golden CO: National Renewable Energy Laboratory; 2008. Technical Report NREL/TP-510-42618.

38. Yang $H Y$, Wang $K$, Song $X L$, Xu F, Sun RC: Enhanced enzymatic hydrolysis of triploid poplar following stepwise acidic pretreatment and alkaline fractionation. Process Biochem 2012, 47:619-625.

\section{doi:10.1186/s13068-014-0116-8}

Cite this article as: Sun et al:: Improving the enzymatic hydrolysis of thermo-mechanical fiber from Eucalyptus urophylla by a combination of hydrothermal pretreatment and alkali fractionation. Biotechnology for Biofuels 2014 7:116

\section{Submit your next manuscript to BioMed Central and take full advantage of:}

- Convenient online submission

- Thorough peer review

- No space constraints or color figure charges

- Immediate publication on acceptance

- Inclusion in PubMed, CAS, Scopus and Google Scholar

- Research which is freely available for redistribution 